Cite this: Phys. Chem. Chem. Phys., 2014, 16, 9002

Received 22nd February 2014, Accepted 25th March 2014

DOI: $10.1039 / c 4 c p 00778 f$

www.rsc.org/pccp

\title{
Adsorbate induced vacancy formation on silver surfaces
}

\author{
Travis E. Jones, ${ }^{a b c}$ Tulio C. R. Rocha, ${ }^{c}$ Axel Knop-Gericke, ${ }^{c}$ Catherine Stampfl, ${ }^{b}$ \\ Robert Schlögl ${ }^{C}$ and Simone Piccinin ${ }^{a}$
}

\begin{abstract}
The energy required to form and remove vacancies on metal surfaces mediates the rate of mass transport during a wide range of processes. These energies are known to be sensitive to environmental conditions. Here, we use electronic structure density functional theory calculations to show that the surface vacancy formation energy of silver changes markedly in the presence of adsorbed and dissolved oxygen. We found that adsorbed atomic oxygen can reduce the surface vacancy formation energy of the $\mathrm{Ag}(111)$ surface by more than $30 \%$, whereas surface vacancy formation becomes exothermic in the presence of pure subsurface oxygen. We went on to show that the total directionality of the topologically defined bond paths can be used to understand these changes. The resulting structure-property relationship was used to predict the behavior of silver in different atmospheres. We show that the surface vacancy formation energy decreases when electronegative elements are adsorbed on the surface, but that it can increase when electropositive elements are adsorbed.
\end{abstract}

\section{Introduction}

Vacancies are important defects in fcc metals and are the primary channels for mass transport on metal surfaces. ${ }^{1,2}$ During processes such as faceting and coarsening, vacancy formation and migration energies determine the rate of mass transport. ${ }^{3-5}$ The adsorption of gases, or alloying, will change these energies. ${ }^{6-9}$ By understanding these changes, it may be possible to exploit them in the design of new materials, such as lead free solders, ${ }^{10}$ creep resistant alloys, ${ }^{11,12}$ and better catalysts. ${ }^{13,14}$ To this end, here, we report an investigation of the atmospheric effects on the surface vacancy formation energies of silver.

Silver is a classic example of a metal whose surface selfdiffusion is dependent on the atmosphere. It has long been known that silver surfaces are etched to show simple crystallographic planes at high temperature in air. ${ }^{15,16}$ And because silver can be thermally etched in air at standard atmospheric pressure, unlike other metals that require a more restrictive atmosphere, it has been the focus of numerous experimental investigations. $^{15-19}$

These studies have revealed that the surface self-diffusion of silver increases markedly in an oxygen atmosphere at temperatures

\footnotetext{
${ }^{a}$ CNR-IOM Democritos, c/o SISSA, via Bonomea 265 I-34136, Trieste, Italy. E-mail: trjones@mines.edu

${ }^{b}$ School of Physics, The University of Sydney, Sydney, New South Wales 2006, Australia

${ }^{c}$ Department of Inorganic Chemistry, Fritz-Haber-Institut der Max-Planck-Gesellschaft, Faradayweg 4-6, 14195, Berlin, Germany
}

above $700 \mathrm{~K}$ as compared to an oxygen free atmosphere. ${ }^{17-19}$ At temperatures below $700 \mathrm{~K}$, an oxygen atmosphere is known to produce a $p(4 \times 4)$ surface reconstruction of the $\operatorname{Ag}(111)$ surface, ${ }^{20-23}$ whereas above $700 \mathrm{~K}$ the presence of oxygen induces grain boundary grooving and faceting. ${ }^{24-26}$ However, these temperatures are too low to lead to the formation of sufficient vacancies in vacuo to result in the morphological changes observed under an $\mathrm{O}_{2}$ atmosphere. ${ }^{27}$ Clearly, oxygen plays an important role in reducing the surface vacancy formation energy of silver, as it does for chromium ${ }^{28}$ and ruthenium. ${ }^{29}$

In order to elucidate the effect of oxygen on the vacancy formation energy of silver, the function of a variety of oxygen species must be considered. Surface science studies have revealed that at temperatures above $700 \mathrm{~K} \mathrm{O}_{2}$ dissociatively adsorbs onto the $\mathrm{Ag}(111)$ surface, resulting in three types of coadsorbed oxygen species. ${ }^{26}$ The first of these, $\mathrm{O}_{\text {ads }}$, is thought to be adsorbed atomic oxygen, which is present at surface coverages up to $1 / 4$ of a monolayer (ML). ${ }^{26,27,30,31}$ Beyond this concentration, subsurface oxygen becomes energetically favorable ${ }^{32}$ and is thought to appear as a new species, $\mathrm{O}_{\mathrm{ss}}$, that may coexist with $\mathrm{O}_{\text {ads }}{ }^{26,33}$ As the concentration of the subsurface species increases beyond 1/4-1/2 ML at temperatures above $700 \mathrm{~K}$, a substitutional species, $\mathrm{O}_{\text {sub }}$, is thought to form. The formation of this species coincides with the disappearance of $\mathrm{O}_{\text {ads }}$ and $\mathrm{O}_{\mathrm{ss}}$, which has prompted researchers to suggest $\mathrm{O}_{\mathrm{ads}}$ and $\mathrm{O}_{\mathrm{ss}}$ transformation into $\mathrm{O}_{\text {sub }} \cdot{ }^{24-26}$ Large morphological changes are also associated with the formation of the substitutional species. ${ }^{34-37}$ Thus, $\mathrm{O}_{\text {ads }}$ and $\mathrm{O}_{\mathrm{ss}}$ are likely responsible for 
the change in vacancy formation energy that allows the formation of the $\mathrm{O}_{\text {sub }}$ species and the subsequent thermal etching.

To investigate the role these species play in vacancy formation, we calculated the surface vacancy formation energy of silver in their presence and absence by way of electronic structure density functional theory (DFT). We went on to develop structure-property relationships by correlating topological and geometric features of the electron charge density, $\rho(\vec{r})$, with our calculated vacancy formation energies. An advantage of developing structure-property relationships using $\rho(\vec{r})$ is that the charge density is a quantum mechanical observable. And because all ground state properties are a consequence of $\rho(\vec{r}),{ }^{38}$ the gas phase $^{39,40}$ and the solid state, ${ }^{40-42}$ processes occurring near the silver surface during vacancy formation in the presence of adsorbates can be described in the same framework. Importantly, in this work, the topological and geometric structure of $\rho(\vec{r})$ has been used to uncover the atomic scale properties that mediate the ideal work of fracture, a process that shares many features with surface vacancy formation. ${ }^{43,44}$

\section{Topological model of bonding}

Because $\rho(\vec{r})$ is a three dimensional scalar field, Morse theory tells us that its topology can be partially characterized by its rank three critical points (CPs). ${ }^{45,46}$ In a three dimensional field, there are four types of non-degenerate CP: a local maximum, local minimum, and two types of saddle point, which are commonly identified using the (rank, signature) notation. For a non-degenerate critical point the rank of the second derivative matrix, the Hessian, is always equal to the dimensionality of the space, for our cases it is three. The signature is the number of positive curvatures minus the number of negative curvatures. A maximum would then be denoted $(3,-3)$ and a minimum $(3,+3)$. The saddle point with two negative curvatures would be denoted as $(3,-1)$ and the saddle with two positive curvatures a $(3,+1) \mathrm{CP}$.

Extensive theoretical and experimental studies have demonstrated that the topological properties of $\rho(\vec{r})$ correlate with elements of solid state structure and bonding. ${ }^{39-42,47-50}$ In particular, the locations of nuclei coincide with $(3,-3)$ CPs, while a bond path has been shown to coincide with the existence of a ridge of maximum charge density connecting bound nuclei. ${ }^{51-54}$ A necessary and sufficient condition for the existence of such a ridge in the solid state is the presence of a $(3,-1) \mathrm{CP}$. Thus, this CP is often referred to as a bond CP. The other two types of CP also correlate with features of solid state structure. A cage structure must enclose a single $(3,+3) \mathrm{CP}$, which is often denoted a cage $\mathrm{CP}$, while a $(3,+1) \mathrm{CP}$ is topologically required in ring structures, and is denoted a ring $\mathrm{CP} .{ }^{54-56}$

By way of example, Fig. 1 shows the topological bonding features of a $\operatorname{Ag}(111)$ surface with and without a surface vacancy. The left panel of the figure shows a traditional ball and stick plot of the surface. A charge density contour plot of this cut plane is shown to the right, with the minima colored black. Inspection of the figure reveals that each surface atom is a maximum in $\rho(\vec{r})$, corresponding to the nuclear positions in
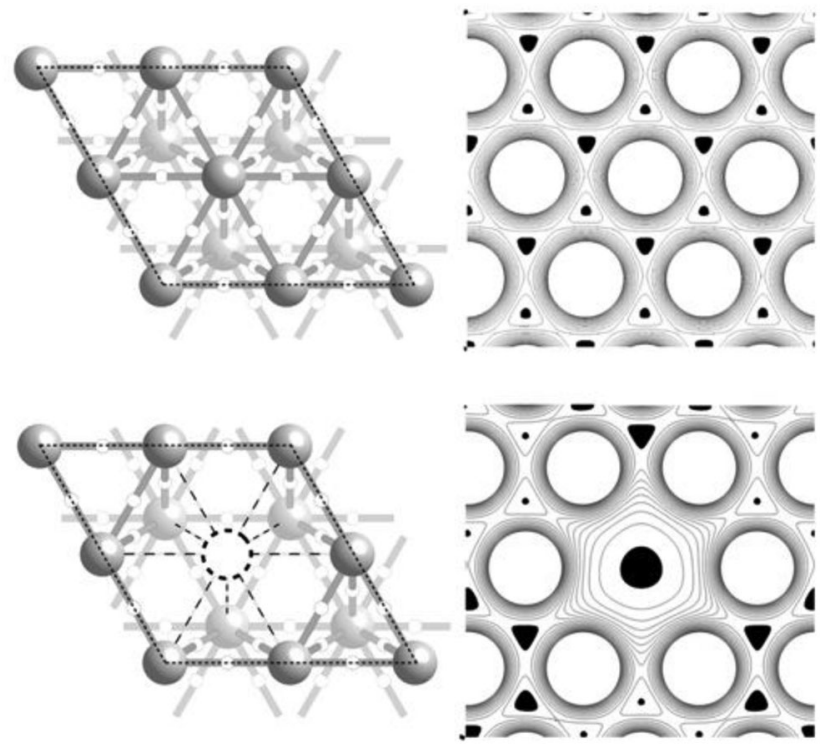

Fig. $1 \mathrm{Ag}(111)$ surface without (top) and with (bottom) a surface vacancy. A ball and stick model of each surface is shown on the left. The thin black dashed line shows the $(2 \times 2)$ unit cell. The dark gray spheres represent nuclear sites in the top layer. The light gray spheres represent nuclear sites in the bottom layer, and the white circles represent bond points. The bond paths are shown by way of gray lines connecting nuclear sites. The position of the surface vacancy is indicated with a dashed circle, and the lost bond paths are shown by dashed lines. The corresponding charge density contour plots in the two Ag(111) surfaces are shown on the left, with the minima colored black. The nuclear sites appear as maxima, the bond points, as saddle points connecting neighboring maxima, and the surface vacancy as a minimum.

the ball and stick representation. A ridge can be seen to connect nearest neighbor maxima in the contour plot, as evident by the saddle points connecting each maxima to its six nearest neighbors. These saddle points are the $(3,-1)$ bond points, while the ridge is the bond path, shown by way of the gray cylinders connecting atoms in the ball and stick plot. When a surface atom is removed, six of the surface bond paths are lost, as shown in the lower panel of Fig. 1. These topological features allow us to unambiguously uncover the changes in the number and type of bond paths that occur in silver in the presence and absence of adsorbates. However, because the topology has no metric that allows differentiation between $\mathrm{Ag}-\mathrm{O}$ and $\mathrm{Ag}-\mathrm{Ag}$ bonding, the number of bond paths alone cannot be used to describe vacancy formation in silver, as will be discussed in Section 5. Bond path properties must also be included.

One potentially useful property is directionality, which has been used to rationalize other processes involving bond breaking in metals, including the cleavage behavior of bcc metals ${ }^{57}$ and Ir. ${ }^{58}$ Directionality has been quantified using the quadratic surface constructed from the Hessian of $\rho(\vec{r})$ at the bond CPs. ${ }^{57-61}$ This surface is the elliptic cone shown in Fig. 2 whose extreme angles are given by:

$$
\tan \theta=\sqrt{\frac{\rho_{\perp \perp}}{\rho_{\|\|}}} \text {and } \tan \phi=\sqrt{\frac{\rho_{\perp^{\prime} \perp^{\prime}}}{\rho_{\|\|}}}
$$




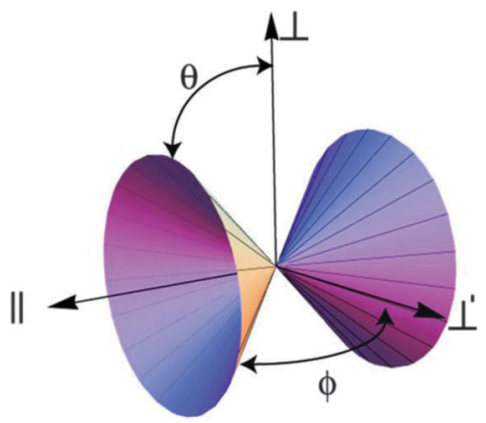

Fig. 2 The elliptic cone formed by the locus of directions of zero curvature at a bond point. The angles $\theta$ and $\phi$ are defined in eqn (1)

where $\rho_{\perp \perp}$ and $\rho_{\perp^{\prime} \perp^{\prime}}$ are the principal curvatures of the electron charge density at the bond point in the directions perpendicular to the bond path, and $\rho_{\|\|}$is the curvature of $\rho(\vec{r})$ along the bond path.

To facilitate visualization the elliptic cone formed by the locus of directions of zero curvature at a bond point on the $\mathrm{Ag}(111)$ surface is shown in Fig. 3. It has been projected into the plane containing the directions of principal curvature of the charge density parallel and normal to the bond path, those used to define $\rho_{\|\| \|}$and $\rho_{\perp \perp}$ in Fig. 3a. The angle of the cone with respect to the $\perp$ direction is $\theta$. A similar representation of $\phi$ is shown in Fig. 3b, in which case the charge density cut plane again contains the direction of principal curvature parallel and normal to the bond path. However, in this case, the normal direction is taken as that used to define $\rho_{\perp^{\prime} \perp^{\prime}}$. The angle the cone makes with the $\perp^{\prime}$ direction is $\phi$.

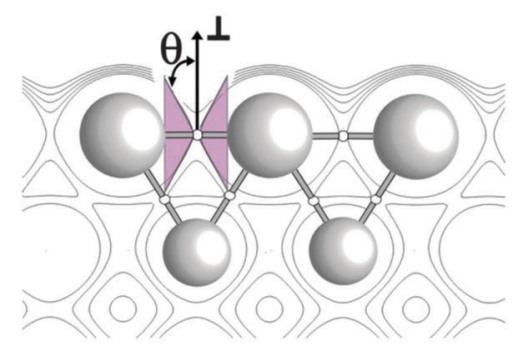

(a) $\theta$

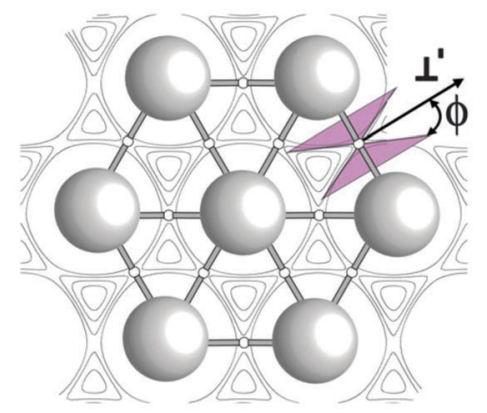

(b) $\phi$

Fig. 3 The elliptic cone formed by the locus of directions of zero curvature at a bond point in a $\mathrm{Ag}(111)$ surface viewed from the directions of principal curvature normal to the bond path.
This definition offers a measure of the distance to bond breaking. Bond points can only be destroyed through a topological catastrophe in which one, or both, of the curvatures perpendicular to the bond path vanish. ${ }^{55,62-65}$ Such a catastrophe will occur when the elliptic cone at the bond CP transforms into intersecting planes. The angle of the elliptic cone formed by the locus of directions of zero curvature at a bond point will go to zero as the cone collapses. The cone will preferentially collapse in the direction of the smaller angle at a rate proportional to the value of the charge density at the bond $\mathrm{CP}, \rho_{0} \cdot{ }^{61,66,67}$ Thus, the perturbation required to cause the topological catastrophe is proportional to the lower of the two values: $\rho_{0} \tan \theta$ and $\rho_{0} \tan \phi$, which we will report as $\left(\rho_{0} \tan \theta\left[\mathrm{e} \AA^{-3}\right]\right.$, $\left.\rho_{0} \tan \phi\left[\mathrm{e} \AA^{-3}\right]\right)$ for brevity.

As we will show below, using the topology of the charge density to define bond paths and the geometry $\rho(\vec{r})$ to define directionality allows us to uncover structure-property relationships that describe vacancy formation in silver using different adsorbates and the role of alloying. Once identified, these relationships can be used to develop strategies to modify the vacancy formation energy.

\section{Methods}

We performed spin-restricted DFT calculations using the Quantum Espresso $(\mathrm{QE})$ package $^{68}$ and ultrasoft pseudopotentials with a kinetic energy cutoff of $30 \mathrm{Ry}$ for the wavefunctions and 300 Ry for the charge density. The generalized gradient approximation (GGA) developed by Perdew, Burke, and Ernzerhof ${ }^{69}$ was employed on a $(12 \times 12 \times 1)$ Monkhorst-Pack $k$-point mesh $^{70}$ for the $(1 \times 1)$ surface unit cell. Marzari-Vanderbilt cold smearing with a width of 0.02 Ry was used to improve convergence. ${ }^{71}$ The charge density analysis was done using the TECD software package. ${ }^{72}$

All calculations were performed on a five layer $\mathrm{Ag}(111)$ slab that was separated from its periodic images with approximately five layers of vacuum. The in-plane dimensions of the $(1 \times 1)$ surface unit cell were fixed at $2.93 \AA$ using the bulk silver lattice constant we calculated within QE, which is within $2 \%$ of the experimentally measured value. ${ }^{73}$ The atomic coordinates were allowed to relax, except the bottom layer of silver, which was held fixed. And because the minimum concentration of $\mathrm{O}_{\mathrm{ads}}$ needed to form the subsurface species is thought to be $1 / 4 \mathrm{ML}$, we chose to employ a $(2 \times 2)$ surface for all of the calculations.

Surface vacancy formation energies of both pure silver and silver with the different adsorbates were calculated as:

$$
E_{\mathrm{vac}}=\left(E_{\mathrm{Ag}}^{\mathrm{bulk}}+E_{\mathrm{Ag}}^{\mathrm{vac}}\right)-E_{\mathrm{surf}},
$$

where $E_{\mathrm{Ag}}^{\text {bulk }}$ is the energy of a bulk silver atom, $E_{\text {surf }}$ is the energy of the fully relaxed surface without a vacancy but with any adsorbate, and $E_{\mathrm{Ag}}^{\mathrm{vac}}$ is the energy of the same surface and adsorbate with a single silver surface vacancy, which we calculated with and without ionic relaxation. When the surface vacancy formation energy, as defined in eqn (2), is positive, forming the vacancy increases the total energy of the system. 
Hence, a positive vacancy formation energy is found when vacancy formation is not energetically favorable. Conversely, a negative value of $E_{\text {vac }}$ corresponds to a situation in which vacancy formation is energetically favorable as, in this case, the system can lower its total energy by introducing a surface vacancy.

The projected density of states (PDOS) were calculated as:

$$
N_{\alpha}=\sum_{i=1}^{\infty}\left|\left\langle\phi_{\alpha}(\mathbf{r}) \mid \varphi_{i}(\mathbf{r})\right\rangle\right|^{2} \delta\left(\varepsilon-\varepsilon_{i}\right),
$$

where the $\phi_{\alpha}(\mathbf{r})$ 's are the eigenfunctions contained in the pseudopotentials on which the eigenfunctions of the Kohn-Sham Hamiltonian, $\varphi_{i}(\mathbf{r})$, are projected.

\section{Results}

\subsection{Clean surface}

Table 1 summarizes the vacancy formation energies associated with the various oxygen species on the $\mathrm{Ag}(111)$ surface. Inspection of the table reveals that $E_{\mathrm{vac}}$ of a clean $\mathrm{Ag}(111)$ surface is $0.48 \mathrm{eV}$ without ionic relaxation and is $0.46 \mathrm{eV}$ with relaxation, in good agreement with $\mathrm{Li}$ et al.'s value of $0.44 \mathrm{eV}^{27,30} \mathrm{As}$ expected, the surface vacancy formation energy is substantially lower than the bulk vacancy formation energy, which we calculated to be $0.84 \mathrm{eV}$ without relaxation and $0.81 \mathrm{eV}$ with relaxation, in agreement with previous theoretical work, $0.80 \mathrm{eV}^{74}$ and $0.86 \mathrm{eV},{ }^{75}$ but approximately $0.2 \mathrm{eV}$ below the vacancy formation energies derived from positron annihilation, $0.99-1.10 \mathrm{eV}{ }^{76,77}$ quenching, $1.10 \mathrm{eV},{ }^{1,78}$ and length change experiments, $1.09 \mathrm{eV}^{79}$

On the pristine surface, the ionic relaxation is small as suggested by the small reduction in surface vacancy formation energy that accompanies relaxation which principally serves to reduce the interlayer spacing in the [111] direction upon formation of the surface vacancy. We found that while the distance between nearest neighbor surface atoms remains unchanged after surface vacancy formation, the interlayer spacing drops from $2.39 \AA$ on the defect free surface to $2.33 \AA$ upon relaxation with the surface vacancy present. This contraction of the top layer of silver serves to compensate for the loss of bonding associated with the formation of the surface vacancy shown in Fig. 1.

This loss in bonding associated with vacancy formation is also manifested in the PDOS. The solid lines in Fig. $4 \mathrm{a}$ and $\mathrm{b}$

Table 1 Unrelaxed and relaxed vacancy formation energies in eV for various $\mathrm{Ag}(111) / O$ species. When oxygen is present, two types of silver surface vacancies can be formed; those which break $\mathrm{Ag}-\mathrm{Ag}$ bonds only $\left(\mathrm{Ag}_{\mathrm{Ag}}\right)$ and those that break $\mathrm{Ag}-\mathrm{Ag}$ and $\mathrm{Ag}-\mathrm{O}$ bonds $\left(\mathrm{Ag}_{\mathrm{O}}\right)$

\begin{tabular}{lllcc}
\hline Surface & Vacancy & $E_{\text {vac }}^{\text {unrelax }}$ & $E_{\text {vac }}^{\text {relax }}$ & BCPs \\
\hline Clean & $\mathrm{Ag}$ & 0.48 & 0.46 & 9 \\
$\mathrm{O}_{\text {ads }}$ & $\mathrm{Ag}_{\mathrm{O}}$ & 1.07 & - & 8 \\
$\mathrm{O}_{\text {ads }}$ & $\mathrm{Ag}_{\mathrm{Ag}}$ & 0.16 & 0.14 & 9 \\
$\mathrm{O}_{\text {ads }} \& \mathrm{O}_{\text {ss }}$ & $\mathrm{Ag}_{\mathrm{O}}$ & 1.12 & - & 6 \\
$\mathrm{O}_{\text {ads }} \& \mathrm{O}_{\mathrm{ss}}$ & $\mathrm{Ag}_{\mathrm{Ag}}$ & 0.26 & 0.21 & 9 \\
$\mathrm{O}_{\mathrm{ss}}$ & $\mathrm{Ag}_{\mathrm{O}}$ & 0.53 & -0.16 & 7 \\
$\mathrm{O}_{\text {ss }}$ & $\mathrm{Ag}_{\mathrm{Ag}}$ & 0.15 & 0.11 & 9
\end{tabular}

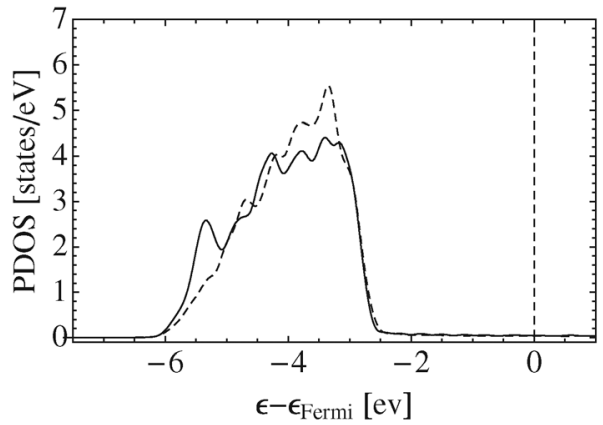

(a) surface

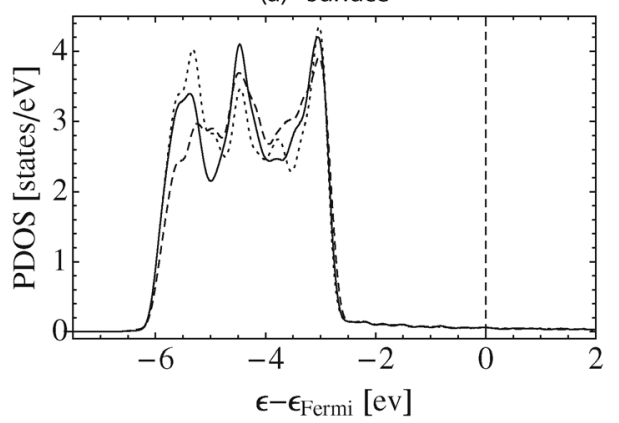

(b) subsurface

Fig. 4 The solid black line shows the Ag d-states on the surface (a) and subsurface (b) atoms for the clean Ag(111) surface without a surface vacancy. The dashed lines show the corresponding systems after the introduction of the surface vacancy. The dotted line in (b) shows the d-states on bulk silver.

show the d-states of the silver atoms on the pristine surface in the topmost layer and in the first subsurface layer, respectively. For comparison, the dotted line in Fig. $4 \mathrm{~b}$ shows the d-states on a bulk fcc silver atom. In all cases the d-states appear between 2.5-6 eV below the Fermi energy, $\varepsilon_{\mathrm{F}}$, which is set to zero and shown by way of the vertical dashed line in Fig. 4 .

The PDOS on the surface atoms is narrower than in the bulk. This narrowing is due to both the reduction in the number of bond paths terminating at the surface atoms from 12 in the bulk to 9 on the surface, and the fact that the directionality of the bond paths connecting nearest neighbor surface atoms, $(0.047,0.068)$, is less than the directionality of the bond paths in the bulk, $(0.079,0.087)$.

The directionality of the bond paths connecting surface and subsurface atoms, $(0.071,0.088)$, is close to that found in the bulk. Furthermore, the full complement of 12 bond paths terminate at the subsurface atoms. As a result, the d-states on the subsurface silver atoms can be seen to strongly resemble those in bulk silver, Fig. $4 \mathrm{~b}$.

Fig. 4 also shows that further narrowing of the surface silver d-states relative to the bulk is observed when a surface vacancy is introduced, the dashed line in Fig. 4a. In this case, the response of d-states of the silver surface atoms at the vacancy edge is due to the reduction in the number of bond paths terminating at those atoms, from nine to eight bond paths, as the directionality of the remaining bond paths connecting surface atoms remains almost unchanged, (0.051, 0.068), 
from those on the pristine surface. While the same effect can also be seen in the subsurface, the dashed line in Fig. $4 \mathrm{~b}$, the subsurface atoms at the vacancy edge retain 11 bond paths. As such, the d-states on these atoms still resemble those of bulk fcc silver more than the d-states on the surface atoms.

\subsection{Adsorbed oxygen}

When 1/4 ML adsorbed oxygen is introduced, it preferentially adsorbs on the fcc hollow site, ${ }^{27}$ causing changes in the bonding on the silver surface. Fig. 5a shows a ball and stick model of a $\mathrm{Ag}(111)$ surface with $1 / 4 \mathrm{ML}$ adsorbed oxygen. The black dashed line represents the surface unit cell, each of which contains a single adsorbed oxygen atom, shown by way of a red sphere.

Inspection of Fig. 5a reveals that the presence of adsorbed oxygen lowers the symmetry of the surface, resulting in two symmetry unique surface silver atoms. One is bound to other silver atoms only. It is denoted $\mathrm{Ag}_{\mathrm{Ag}}$ in Table 1 and represented by black spheres in Fig. 5a. As indicated in Table 1 the bonding topology associated with the $\mathrm{Ag}_{\mathrm{Ag}}$ atoms is unchanged from the clean surface, with nine bond paths terminating at the $\mathrm{Ag}_{\mathrm{Ag}}$ atoms. The second type of silver surface atom is bound to oxygen and silver. It is denoted $\mathrm{Ag}_{\mathrm{O}}$ in Table 1 and represented by light gray spheres in Fig. 5a. Unlike the atoms on the clean surface only eight bond paths terminate at the $\mathrm{Ag}_{\mathrm{O}}$ atoms because each $\mathrm{Ag}_{\mathrm{O}}$ atom is not bound to all six nearest neighbor surface silvers. In particular, each $\mathrm{Ag}_{\mathrm{O}}$ atom sacrifices two $\mathrm{Ag}_{\mathrm{O}}-\mathrm{Ag}_{\mathrm{O}}$ bond paths to form a single $\mathrm{Ag}_{\mathrm{O}}-\mathrm{O}$ bond path. These changes in bonding are accompanied by changes in the atomic structure.

The internuclear distances between nearest neighbor atoms are shown in Fig. 5. The distance between the bound $\mathrm{Ag}_{\mathrm{O}}$ atoms

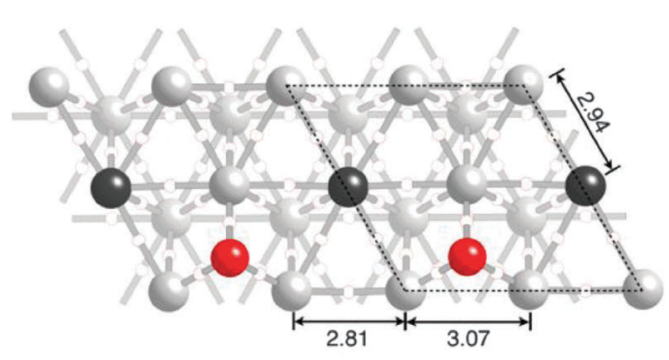

(a) $\mathrm{O}_{a d s}$

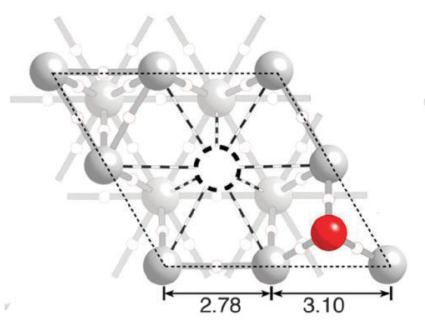

(b) $\mathrm{Ag}_{\mathrm{Ag}}$ vacancy

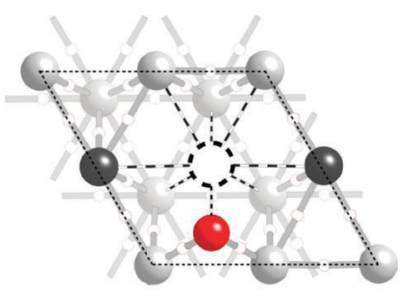

(c) Ago vacancy
Fig. 5 Ball and stick model of a $\mathrm{Ag}$ (111) surface with adsorbed oxygen (a). A surface vacancy at the $\mathrm{Ag}_{\mathrm{Ag}}$ position is shown in (b) and at the Ago position in (c). The vacancies are indicated by way of a dashed circle. The bond path lost upon vacancy formation is indicated by the dashed lines. is $2.81 \AA$, somewhat less than the $2.94 \AA$ seen on the clean $\mathrm{Ag}(111)$ surface. The decrease in the distance between bound $\mathrm{Ag}_{\mathrm{O}}$ atoms is accompanied by a compensatory increase in the internuclear separation between the nearest neighbor unbound $\mathrm{Ag}_{\mathrm{O}}$ atoms to $3.07 \AA$. The $\mathrm{Ag}_{\mathrm{O}}-\mathrm{Ag}_{\mathrm{Ag}}$ distance remains unchanged from that seen on the clean surface, $2.94 \AA$. Adsorbed oxygen tends to pull the $\mathrm{Ag}_{\mathrm{O}}$ atoms away from the underlying $\mathrm{Ag}(111)$ subsurface, thereby increasing the interlayer spacing in the [111] direction from the $2.39 \AA$ found for the clean surface to $2.46 \AA$. There is a concomitant reduction in the $\mathrm{Ag}_{\mathrm{Ag}}$ interlayer separation to $2.30 \AA$.

Like in the case of the pristine surface, the changes in bonding seen in the topology of $\rho(\vec{r})$ that drive the observed changes in geometry are also apparent in the PDOS. Fig. 6 shows the silver d-states on the $\mathrm{Ag}_{\mathrm{Ag}}$ and the $\mathrm{Ag}_{\mathrm{O}}$ atoms by way of solid and dashed black lines, respectively. The oxygen p-states are shown using a dotted blue line.

On the defect free surface, Fig. 6a, the oxygen p-states can be seen to hybridize strongly with the $\mathrm{Ag}_{\mathrm{O}} \mathrm{d}$-states leading to very directional $\mathrm{Ag}_{\mathrm{O}^{-}} \mathrm{O}$ bond paths, $(0.218,0.300)$. The $\mathrm{Ag}_{\mathrm{Ag}} \mathrm{d}$-states do not mix appreciably with the oxygen p-states. As such, the changes in the $\mathrm{Ag}_{\mathrm{Ag}}$ d-states relative to the clean surface are instead due to oxygen induced differences in $\mathrm{Ag}_{\mathrm{Ag}}-\mathrm{Ag}_{\mathrm{O}}$ bonding, which cause a decrease in the directionality of the $\mathrm{Ag}_{\mathrm{Ag}}-\mathrm{Ag}_{\mathrm{O}}$ bond paths and an increase in that of the $\mathrm{Ag}_{\mathrm{O}}-\mathrm{Ag}_{\mathrm{O}}$ bond paths, resulting in $(0.044,0.064)$ and $(0.065,0.086)$, respectively. The influence of oxygen is also apparent in the subsurface. The directionality of the bond paths originating in the subsurface and terminating at the surface $\mathrm{Ag}_{\mathrm{O}}$ atoms is $(0.065,0.094)$, and the directionality of those terminating at the $\mathrm{Ag}_{\mathrm{Ag}}$ atoms is $(0.045,0.064)$.

These differences in bonding have a dramatic effect on the surface vacancy formation energy. The presence of adsorbed

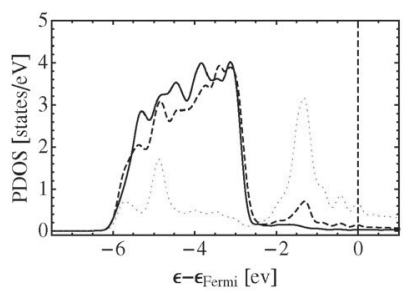

(a) $\mathrm{O}_{\text {ads }}$ without vacancy (b) $\mathrm{Ag}_{\mathrm{Ag}}$ vacancy

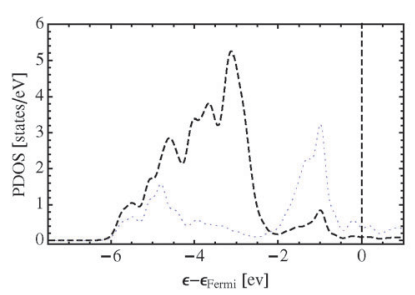

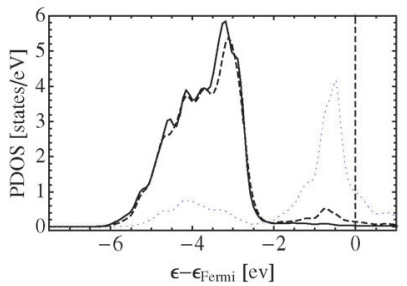

(c) Ago vacancy
Fig. 6 PDOS on the surface silver and oxygen in the $O_{\text {ads }}$ system. The $\mathrm{Ag}_{\mathrm{Ag}} \mathrm{d}$-states are shown using solid lines, the Ago d-states as dashed lines, and the $O \mathrm{p}$-states as dotted blue lines. The system is shown without a surface vacancy (a), with a $\mathrm{Ag}_{\mathrm{Ag}}$ vacancy (b), and with a Ago vacancy (c). 
oxygen decreases the unrelaxed surface vacancy formation energy of $\mathrm{Ag}_{\mathrm{Ag}}$ to $0.16 \mathrm{eV}$ and increases that of $\mathrm{Ag}_{\mathrm{O}}$ to $1.07 \mathrm{eV}$.

The bonding topologies associated with $\mathrm{Ag}_{\mathrm{Ag}}$ and $\mathrm{Ag}_{\mathrm{O}}$ vacancy structures are shown in Fig. 5b and c, respectively. In these figures, the position of the surface vacancy is indicated by way of a dashed circle and the bond paths lost upon vacancy formation are shown by way of dashed lines. Formation of the $\mathrm{Ag}_{\mathrm{Ag}}$ vacancy can be seen to result in the loss of $\mathrm{Ag}-\mathrm{Ag}$ bonding, whereas formation of the $\mathrm{Ag}_{\mathrm{O}}$ vacancy leads to a loss in both $\mathrm{Ag}-\mathrm{Ag}$ and Ag-O bonding.

The different bonding topologies are mirrored in the PDOS. Fig. $6 \mathrm{~b}$ shows that when the $\mathrm{Ag}_{\mathrm{Ag}}$ vacancy is formed the $\mathrm{Ag}_{\mathrm{O}}$ d-states become narrower, as was observed on the clean surface, but still hybridize strongly with the oxygen p-states. Note that in this case there are no $\mathrm{Ag}_{\mathrm{Ag}} \mathrm{d}$-states because the $\mathrm{Ag}_{\mathrm{Ag}}$ atoms have been removed. Conversely, when the $\mathrm{Ag}_{\mathrm{o}}$ vacancy is formed both types of surface silver atoms remain. The PDOS on both types of surface silver becomes narrower, and the mixing between the oxygen p-states and $\mathrm{Ag}_{\mathrm{O}} \mathrm{d}$-states is greatly reduced, confirming the loss in Ag-O bonding seen in Fig. 5c.

As the surface vacancy formation energies indicate, the loss of the very directional $\mathrm{Ag}-\mathrm{O}$ bond paths that occur when the $\mathrm{Ag}_{\mathrm{O}}$ vacancy is formed is energetically unfavorable with respect to the loss of $\mathrm{Ag}-\mathrm{Ag}$ bonding associated with the $\mathrm{Ag}_{\mathrm{Ag}}$ vacancy. When ionic relaxations are allowed, both types of surface vacancies relax into the bonding topology associated with the $\mathrm{Ag}_{\text {Ag }}$ vacancy shown in Fig. 5b with the corresponding PDOS shown in Fig. 6b. Table 1 shows that when ionic relaxations are allowed after an $\mathrm{Ag}_{\mathrm{Ag}}$ vacancy has been formed $E_{\mathrm{vac}}$ stays nearly constant. The minor role of ionic relaxation on the $\mathrm{Ag}_{\mathrm{Ag}}$ vacancy formation energy is a consequence of the fact there is little atomic rearrangement and, hence, little change in bonding upon relaxation. Like in the case of the clean surface, the primary mode of atomic relaxation is a $0.11 \AA$ reduction in the interlayer spacing between the $\mathrm{Ag}_{\mathrm{O}}$ atoms and the subsurface silver, with the distance between nearest neighbor unbound $\mathrm{Ag}_{\mathrm{o}}$ atoms increasing by $0.03 \AA$. If, however, the $\mathrm{Ag}_{\mathrm{o}}$ vacancy system is allowed to relax, the system adopts the atomic configuration associated with the $\mathrm{Ag}_{\mathrm{Ag}}$ vacancy. That is, with relaxation, the structure shown in Fig. 5c transforms into the topologically inequivalent structure shown in Fig. 5b. Thus, the Ag(111) surface with adsorbed $\mathrm{O}$ always prefers to form a $\mathrm{Ag}_{\mathrm{Ag}}$ vacancy.

\subsection{Adsorbed and dissolved oxygen}

When subsurface oxygen is introduced into the $\mathrm{O}_{\text {ads }}$ system we find that the subsurface species preferentially dissolves into the tetrahedral holes to form the oxide-like structure shown in Fig. 7a, in agreement with ref. 32. This geometry preserves the two types of surface silver atoms, $\mathrm{Ag}_{\mathrm{Ag}}$ and $\mathrm{Ag}_{\mathrm{O}}$. However, in this case the $\mathrm{Ag}_{\mathrm{O}}$ atom is bound to oxygen adsorbed on the surface and dissolved in the subsurface, the latter of which is labeled $\mathrm{O}_{\mathrm{ss}}$ in the figure. The additional bonding between silver and subsurface oxygen leads to the loss of all $\mathrm{Ag}_{\mathrm{O}}-\mathrm{Ag}_{\mathrm{O}}$ bond paths. As a result, only six bond paths terminate at each $\mathrm{Ag}_{\mathrm{O}}$ atom. The bonding topology associated with the $\mathrm{Ag}_{\mathrm{Ag}}$ atoms remains unchanged from the clean surface and the $\mathrm{Ag}(111)$ with $\mathrm{O}_{\text {ads }}$ only.

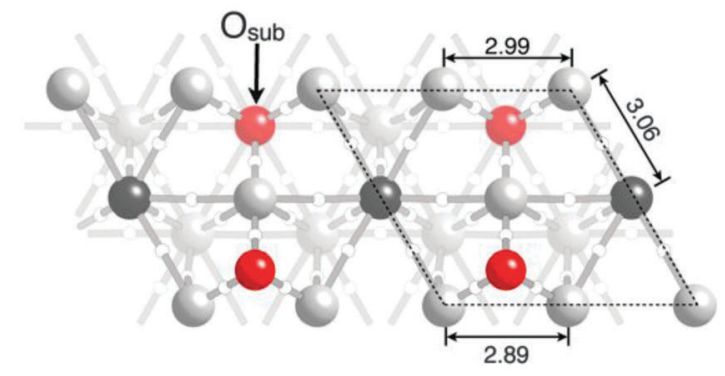

(a) Adsorbed and Dissolved O

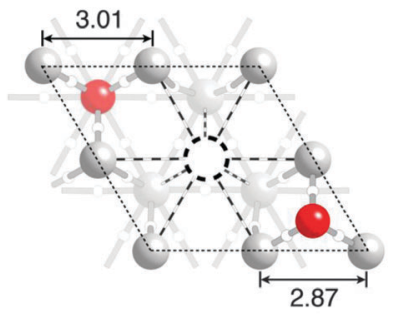

(b) $\mathrm{Ag}_{\mathrm{Ag}}$ vacancy

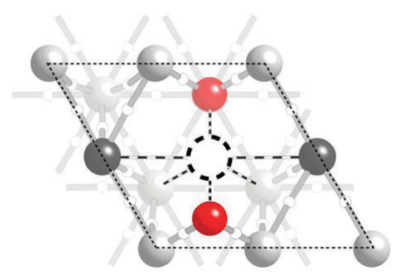

(c) $\mathrm{Ag}_{\mathrm{O}}$ vacancy
Fig. 7 Ball and stick model of a Ag(111) surface with adsorbed and dissolved oxygen (a) using the coloring described in Fig. 5. The subsurface oxygen is labeled $\mathrm{O}_{\text {ss. }}$. The surface $\mathrm{Ag}_{\mathrm{Ag}}$ (b) and $\mathrm{Ag}$ o vacancies (c) are also shown.

The changes in bonding topology associated with introducing $\mathrm{O}_{\mathrm{ss}}$ are manifested in changes to the atomic structure, which are indicated in Fig. 7a. The internuclear separation between nearest neighbor $\mathrm{Ag}_{\mathrm{O}}-\mathrm{Ag}_{\mathrm{O}}$ atoms bound to the same $\mathrm{O}_{\text {ads }}$ reduces from 3.07 $\AA$ when no subsurface oxygen is present to $2.89 \AA$ in the presence of both $\mathrm{O}_{\text {ads }}$ and $\mathrm{O}_{\mathrm{ss}}$. This compression is due to the expansion of the silver atoms around the subsurface oxygen species, which increases the nearest neighbor $\mathrm{Ag}_{\mathrm{O}}-\mathrm{Ag}_{\mathrm{O}}$ distance between silver atoms bound to a common $\mathrm{O}_{\mathrm{ss}}$ atom to $2.99 \AA$ A. The additional subsurface oxygen also increases the interlayer separation between the silver surface and subsurface atoms, with the $\mathrm{Ag}$ o atoms lying $3.20 \AA$ above the subsurface plane in the [111] direction and the $A g_{\text {Ag }}$ at $2.32 \AA$, compared to $2.46 \AA$ and $2.30 \AA$ when only adsorbed oxygen is present. The expansion in the [111] direction also increases the $\mathrm{Ag}_{\mathrm{O}}-\mathrm{Ag}_{\mathrm{Ag}}$ distance to $3.06 \AA$, as compared to $2.94 \AA$ without the subsurface oxygen.

These differences in bonding topology and atomic structure give rise to changes in the PDOS and the bond path directionality. Fig. 8a shows the d-states on $\mathrm{Ag}_{\mathrm{Ag}}$ and $\mathrm{Ag}_{\mathrm{O}}$ with a solid and dashed black line, respectively. The p-states on the adsorbed oxygen are shown with a dotted (blue online) line, and the p-states on the subsurface oxygen are shown by way of a dashed-dotted line (purple online). As is expected from the bonding topology, and as was observed when only adsorbed oxygen is present, appreciable mixing between the oxygen $\mathrm{p}$-states and silver d-states is only seen with $\mathrm{Ag}_{\mathrm{O}}$. Unlike the previous example, however, the addition of subsurface oxygen can be seen to introduce states at approximately $6.5 \mathrm{eV}$ below $\varepsilon_{\mathrm{F}}$ that are formed by a mixture of $\mathrm{O}_{\mathrm{ads}}$ and $\mathrm{O}_{\mathrm{ss}} \mathrm{p}$-states with $\mathrm{Ag}_{\mathrm{O}} \mathrm{d}$-states. The change in bonding induced by $\mathrm{O}_{\mathrm{ss}}$ increases 


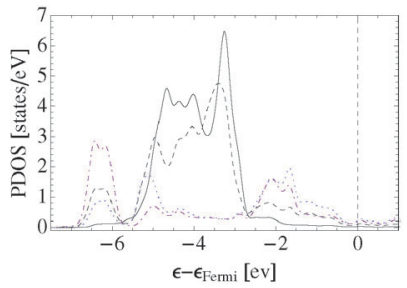

(a) $\mathrm{O}_{\text {ads }} \& \mathrm{O}_{\mathrm{ss}}$ without vacancy

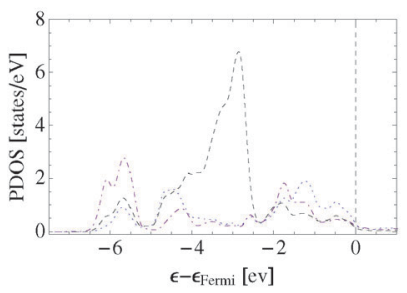

(b) $\mathrm{Ag}_{\text {Ag Vacancy }}$

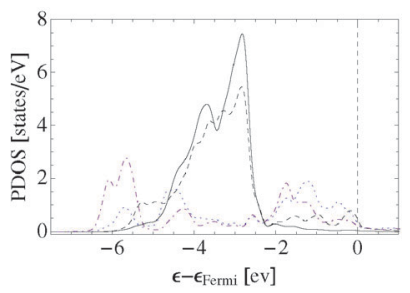

(c) Ago Vacancy
Fig. 8 PDOS on the surface silver and oxygen in the $O_{\text {ads }}$ and $O_{s s}$ systems. The $\mathrm{Ag}_{\mathrm{Ag}} \mathrm{d}$-states are shown using solid lines, the $\mathrm{Ag}$ o $\mathrm{d}$-states dashed lines, the $\mathrm{O}_{\text {ads }} \mathrm{p}$-states dotted lines (blue online), and the $\mathrm{O}_{\mathrm{ss}}$ dashed-dotted lines (purple online). The system is shown without a surface vacancy (a), with a $\mathrm{Ag}_{\mathrm{Ag}}$ vacancy (b), and with a Ago vacancy (c).

the directionality of the $\mathrm{Ag}_{\mathrm{O}}-\mathrm{O}_{\mathrm{ads}}$ bond paths to $(0.256,0.357)$, as compared to the $(0.218,0.300)$ seen in the absence of subsurface oxygen, and leads to the formation of very directional $\mathrm{Ag}_{\mathrm{O}}-\mathrm{O}_{\mathrm{ss}}$ bond paths $(0.239,0.328) . \mathrm{O}_{\mathrm{ss}}$ also modifies the $\mathrm{Ag}_{\mathrm{Ag}}$ states by reducing the $\mathrm{Ag}_{\mathrm{O}}-\mathrm{Ag}_{\mathrm{Ag}}$ bond path directionality to $(0.039,0.059)$.

Despite the differences observed between the silver surface with only adsorbed oxygen and that with both adsorbed and subsurface oxygen, the surface vacancy formation energies are similar. The unrelaxed $\mathrm{Ag}_{\mathrm{Ag}}$ vacancy formation energy in the presence of both $\mathrm{O}_{\text {ads }}$ and $\mathrm{O}_{\mathrm{ss}}$ is $0.26 \mathrm{eV}$, and the unrelaxed $\mathrm{Ag}_{\mathrm{O}}$ surface vacancy formation energy is $1.12 \mathrm{eV}$.

Comparing Fig. $7 \mathrm{~b}$ and c suggests that formation of the $\mathrm{Ag}_{\mathrm{Ag}}$ vacancy is preferred over the $\mathrm{Ag}_{\mathrm{O}}$ due to the fact that the former does not lead to a loss in the directional $\mathrm{Ag}_{\mathrm{O}}-\mathrm{O}$ bonding. The PDOS supports this conclusion. Fig. 8b shows that the mixing between the $\mathrm{Ag}_{\mathrm{O}} \mathrm{d}$ - and oxygen p-states is not strongly perturbed by the presence of the $\mathrm{Ag}_{\mathrm{Ag}}$ vacancy. However, Fig. $8 \mathrm{c}$ reveals that formation of the $\mathrm{Ag}_{\mathrm{o}}$ vacancy leads to a substantial loss in $\mathrm{Ag}_{\mathrm{O}}-\mathrm{O}$ bonding.

When the $\mathrm{Ag}_{\mathrm{Ag}}$ and $\mathrm{Ag}_{\mathrm{O}}$ vacancies are allowed to relax, both adopt the topology associated with the lower energy $\mathrm{Ag}_{\mathrm{Ag}}$ vacancy. Like in the previous example, ionic relaxation has a small effect on the $\mathrm{Ag}_{\mathrm{Ag}}$ surface vacancy formation energy, reducing it by $0.05 \mathrm{eV}$. The principle result of the relaxation of the $\mathrm{Ag}_{\mathrm{Ag}}$ vacancy when both $\mathrm{O}_{\mathrm{ads}}$ and $\mathrm{O}_{\mathrm{ss}}$ are present is a reduction in the interlayer spacing between the surface and subsurface silver in the [111] direction from $3.20 \AA$ to $2.94 \AA$. The nearest neighbor $\mathrm{Ag}_{\mathrm{O}}-\mathrm{Ag}_{\mathrm{o}}$ internuclear separations remain within $0.03 \AA$ of the unrelaxed distances, with the relaxation leading to a minor expansion in the distances around the subsurface oxygen, Fig. 7b.

\subsection{Dissolved oxygen}

If the adsorbed oxygen is removed from the system, leaving only subsurface oxygen, the bonding topology is similar to what was found when only adsorbed oxygen is present. Two symmetry unique surface silver atoms can still be seen, Fig. 9a. And, as in the other cases, nine bond paths terminate at the $\mathrm{Ag}_{\mathrm{Ag}}$ atoms. Here, however, only seven bond paths terminate at the $\mathrm{Ag}_{\mathrm{O}}$ atoms because of the loss of bonding between, not only the nearest neighbor $\mathrm{Ag}_{\mathrm{O}}$ atoms, but the additional loss of a bond path connecting the $\mathrm{Ag}_{\mathrm{O}}$ atoms to the subsurface silver.

Inspection of Fig. 9a further reveals that the changes in internuclear separation that occur when going from the clean surface to the surface with subsurface oxygen are similar to the changes observed when going from the clean surface to oxygen adsorbed on the fcc hollow site. When $\mathrm{O}_{\mathrm{ss}}$ is present the distance between unbound nearest neighbor $\mathrm{Ag}_{\mathrm{O}}$ atoms increases from the $2.94 \AA$ seen on the clean surface to $3.24 \AA$, somewhat larger

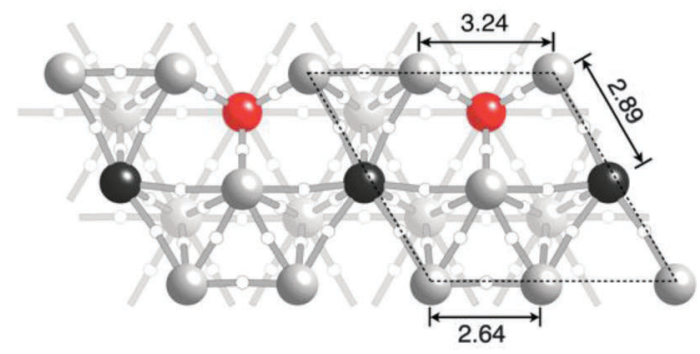

(a) $\mathrm{O}_{s s}$

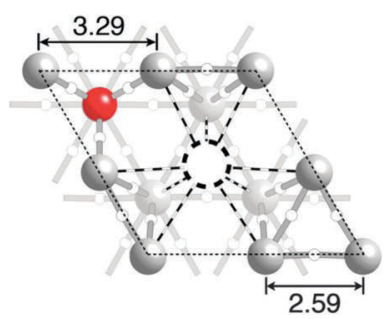

(b) $\mathrm{Ag}_{\mathrm{Ag}}$ vacancy

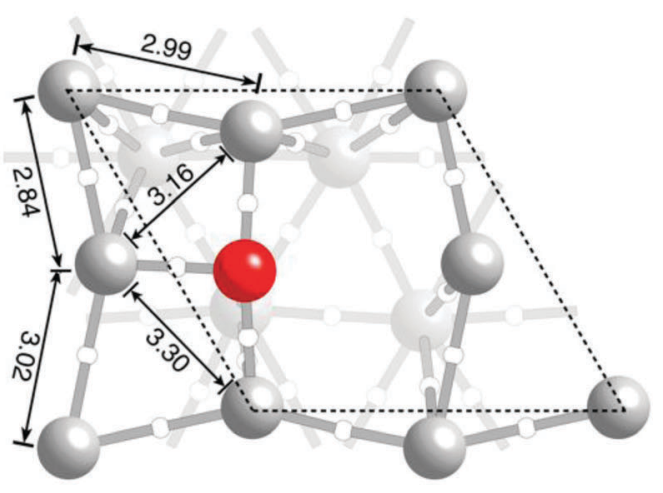

(d) Relaxed Ago vacancy

Fig. 9 Ball and stick model of an Ag(111) surface with dissolved oxygen (a) using the coloring described in Fig. 5. The surface is also shown with a $\mathrm{Ag}_{\mathrm{Ag}}$ vacancy (b) and a Ago vacancy before (c) and after (d) relaxation. 
than the $3.07 \AA$ seen for the case of $\mathrm{O}_{\text {ads }}$. This expansion reduces the internuclear separation between bound $\mathrm{Ag}_{\mathrm{O}}$ atoms to $2.64 \AA$. The interlayer spacing between the $\mathrm{Ag}_{\mathrm{O}}$ atoms and the subsurface silver in the [111] direction increases relatively to the clean surface, while the interlayer spacing between the $\mathrm{Ag}_{\mathrm{Ag}}$ atoms and the subsurface decreases, resulting in $d_{\mathrm{Ag}}=$ $2.89 \AA$ and $d_{\mathrm{Ag}_{\mathrm{Ag}}}=2.35 \AA$.

While the bonding topology and internuclear distances for the system with only subsurface oxygen present resembled the $\mathrm{O}_{\text {ads }}$ system, the PDOS and bond path directionalities of the $\mathrm{O}_{\text {ss }}$ system share characteristics of the system with both $\mathrm{O}_{\text {ads }}$ and $\mathrm{O}_{\mathrm{ss}}$. The black solid and dashed lines in Fig. 10 show the $\mathrm{Ag}_{\mathrm{Ag}}$ and $\mathrm{Ag}_{\mathrm{o}} \mathrm{d}$-states, respectively. The dashed-dotted line (purple online) shows the oxygen p-states. In agreement with the bonding topology, little mixing can be seen between the $\mathrm{Ag}_{\mathrm{Ag}} \mathrm{d}$-states

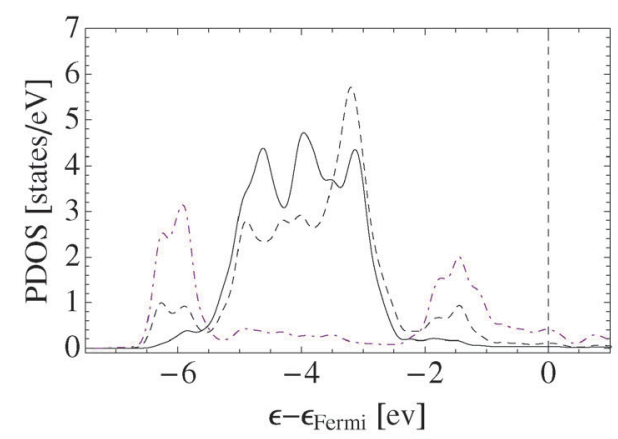

(a) $\mathrm{O}_{\text {ss }}$ without vacancy

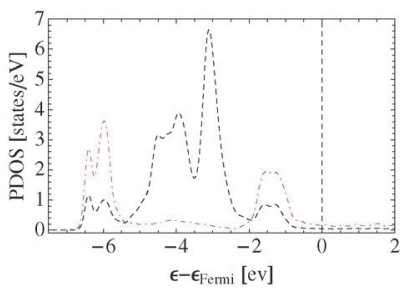

(b) $\mathrm{Ag}_{\mathrm{Ag}}$ Vacancy

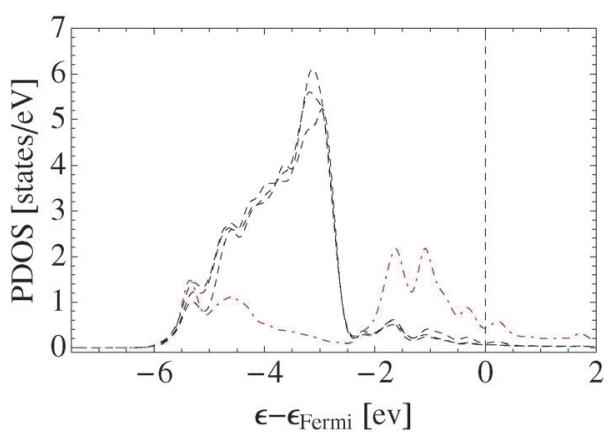

(d) Ago Vacancy Relaxed

Fig. 10 PDOS on the surface silver and oxygen in the $O_{\text {ss }}$ system. The $\mathrm{Ag}_{\mathrm{Ag}} \mathrm{d}$-states are shown using solid lines, the $\mathrm{Ag}$ o $\mathrm{d}$-states as dashed lines. The $\mathrm{O}_{s s} \mathrm{p}$-states are indicated by dashed-dotted lines (purple online). The system is shown without a surface vacancy in (a), with a $\mathrm{Ag}_{\mathrm{Ag}}$ vacancy (b), with an unrelaxed $A_{\circ}$ vacancy (c), and with a $A g_{\circ}$ vacancy after relaxation $(d)$. and $\mathrm{O}_{\mathrm{ss}} \mathrm{p}$-states, whereas the strong $\mathrm{p}-\mathrm{d}$ hybridization between the subsurface oxygen and the $\mathrm{Ag}_{\mathrm{o}}$ gives rise to features at $1.5 \mathrm{eV}$ and $6.0 \mathrm{eV}$ below the Fermi energy. Though the former feature is seen when only adsorbed oxygen is present, the latter is only observed after $\mathrm{O}_{\mathrm{ss}}$ had been introduced. The resulting $\mathrm{Ag}_{\mathrm{O}}-\mathrm{O}$ bond path directionality in this system remains high $(0.216,0.239)$. The changes in mixing between silver d-states induced by $\mathrm{O}_{\mathrm{ss}}$ result in a $\mathrm{Ag}_{\mathrm{O}}-\mathrm{Ag}_{\mathrm{O}}$ bond path directionality of $(0.077,0.112)$, which is more directional than what we found on the other surfaces. Following the trend we have observed in the other cases, the increase in $\mathrm{Ag}_{\mathrm{O}}-\mathrm{Ag}_{\mathrm{O}}$ bond path directionality is accompanied by a decrease in the $\mathrm{Ag}_{\mathrm{Ag}}-\mathrm{Ag}_{\mathrm{O}}$ bond path directionality, in this case to $(0.036,0.052)$, which is close to the directionality of the $\mathrm{Ag}_{\mathrm{Ag}}-\mathrm{Ag}_{\mathrm{O}}$ when both $\mathrm{O}_{\mathrm{ads}}$ and $\mathrm{O}_{\mathrm{ss}}$ are present.

These differences in bonding lead to a striking difference in vacancy formation energies between the surface with only subsurface oxygen present and those with adsorbed oxygen. In the current case, though the unrelaxed $\mathrm{Ag}_{\mathrm{Ag}}$ vacancy formation energy of $0.15 \mathrm{eV}$ is nearly equal to the $0.16 \mathrm{eV}$ found in the $\mathrm{O}_{\text {ads }}$ system, the unrelaxed $\mathrm{Ag}_{\mathrm{o}}$ vacancy formation energy of $0.53 \mathrm{eV}$ is only marginally larger than the $0.48 \mathrm{eV}$ found on the clean surface, Table 1 . Moreover, unlike in the previous examples, both the $\mathrm{Ag}_{\mathrm{Ag}}$ and $\mathrm{Ag}_{\mathrm{O}}$ relax into inequivalent structures with unique bonding topologies.

The ionic relaxations associated with the $\mathrm{Ag}_{\mathrm{Ag}}$ vacancy mirror are those seen in the other examples, Fig. 9b. The unbound nearest neighbor $\mathrm{Ag}_{\mathrm{O}}-\mathrm{Ag}_{\mathrm{O}}$ distance increases by $0.05 \AA$ and the interlayer spacing between the $\mathrm{Ag}_{\mathrm{O}}$ atoms and the subsurface silver in the [111] direction decreases to $2.74 \AA$. The bonding topology shown in Fig. 9b reveals that, as in the previous examples, forming the $\mathrm{Ag}_{\mathrm{Ag}}$ vacancy does not result in the loss of $\mathrm{Ag}_{\mathrm{O}}-\mathrm{O}$ bonding. This view is supported by the PDOS shown in Fig. 10, which indicates that the mixing between the $\mathrm{Ag}_{\mathrm{O}} \mathrm{d}$-states and the $\mathrm{O}_{\mathrm{ss}} \mathrm{p}$-states is not changed appreciably by the introduction of the $\mathrm{Ag}_{\mathrm{Ag}}$ vacancy.

Large atomic relaxations are associated with the $\mathrm{Ag}_{\mathrm{o}}$ vacancy. Fig. 9c shows the system with a $\mathrm{Ag}_{\mathrm{O}}$ vacancy before ionic relaxation, while Fig. 9d shows the same system after relaxation. Comparison of the figures reveals that relaxation leads to the formation of a new $\mathrm{Ag}_{\mathrm{O}}-\mathrm{O}$ bond path, resulting in a substitutional oxygen atom that is bound to all of the remaining surface silver atoms and reducing $E_{\mathrm{vac}}$ to $-0.16 \mathrm{eV}$, i.e. forming a vacancy becomes energetically favorable. The $\mathrm{Ag}_{\mathrm{O}}-\mathrm{O}$ internuclear distances are all roughly similar, and the oxygen lies in the plane of the surface silver atoms, allowing the interlayer spacing between the surface and subsurface silver in the [111] direction to drop below $2.45 \AA$ A. The changes in bonding associated with the relaxation that are seen in the topology of $\rho(\vec{r})$ are also reflected in the PDOS.

Comparing Fig. 10a and c supports the conclusion drawn from the topology of the electron charge density that upon formation of the $\mathrm{Ag}_{\mathrm{O}}$ vacancy silver-oxygen bonding is lost. Furthermore, both the $\mathrm{Ag}_{\mathrm{O}}$ and $\mathrm{Ag}_{\mathrm{Ag}}$ atoms can still be seen to be present in distinct chemical environments, with only the d-states on the $\mathrm{Ag}_{\mathrm{O}}$ atom mixing appreciably with the oxygen p-states. 
When the system relaxes, however, all of the surface silver atoms become nearly equivalent and show mixing between the silver d- and oxygen p-states, Fig. 10d. The PDOS in this relaxed geometry can be seen to be distinct from that seen for $\mathrm{O}_{\mathrm{ss}}$ or $\mathrm{O}_{\text {ads }}$ due to the fact the oxygen has become a surface substitutional species.

In summary, atomic oxygen can significantly alter the surface vacancy formation of silver. The magnitude and direction of these changes depend on the atomic structure of the $\mathrm{Ag}-\mathrm{O}$ system. We will now turn to the origin of this behavior.

\section{Discussion}

\subsection{Descriptor of vacancy formation energy}

In order to gain more quantitative insight into oxygen's effect on the surface vacancy formation energy of silver, we can turn to the oxygen induced changes in bonding. The simplest strategy is to employ a bond path cutting model, i.e. the fewer the bond paths terminating at an atom, the lower its $E_{\mathrm{vac}}$. However, inspection of Table 1 reveals that there is no correlation between the total number of bond paths and $E_{\mathrm{vac}}$. For instance, nine bond paths terminate at every $\mathrm{Ag}_{\mathrm{Ag}}$ atom, yet the surface vacancy formation energies associated with these atoms is markedly different in the various systems. The problem becomes more apparent if we restrict ourselves to comparing unrelaxed surface vacancy formation energies, in which case even a reduction in the number of bond paths can coincide with an increase in $E_{\mathrm{vac}}$. Clearly, the number of bond paths alone is not a good predictor of the vacancy formation energy, and bond path properties must also be included. To begin, consider the differences between silver atoms in the bulk and on an ideal $\operatorname{Ag}(111)$ surface.

We can first imagine a situation in which the surface and bulk bond paths are equivalent, which is a simple bond cutting model. This model would predict that the energy required to remove a surface atom would be $9 / 12$, or $75 \%$, of that in the bulk, because 12 bond paths must be broken to form a bulk vacancy and, as we saw in Section 2, only 9 bond paths are lost when a surface vacancy is formed. However, our calculated surface vacancy formation energy is only $57 \%$ of the bulk value, demonstrating that we must account for the inequivalence of the bond paths.

This inequivalence can be seen in the differences in internuclear separation between bound atoms discussed in Section 4. Internuclear separation, $d$, is often viewed as a measure of bond strength and has been shown to correlate with the magnitude of the electron charge density at the bond point connecting bound atoms, $\rho_{0}$, in molecules ${ }^{80-83}$ and transition metal oxides. ${ }^{82,84}$ In agreement with these studies we see the expected power law dependence of $\rho_{0}$ on internuclear separation between bound atoms, Fig. 11. Furthermore, the regression coefficients of $\rho_{0}=\alpha d^{-\beta}$ are $\alpha=6.489$ and $\beta=3.293$, which are close to the $\alpha=6.795$ and $\beta=3.483$ found for $\mathrm{O}-\mathrm{O}$ bonds in molecules, ${ }^{83}$ suggesting that the correlation may hold on surfaces.

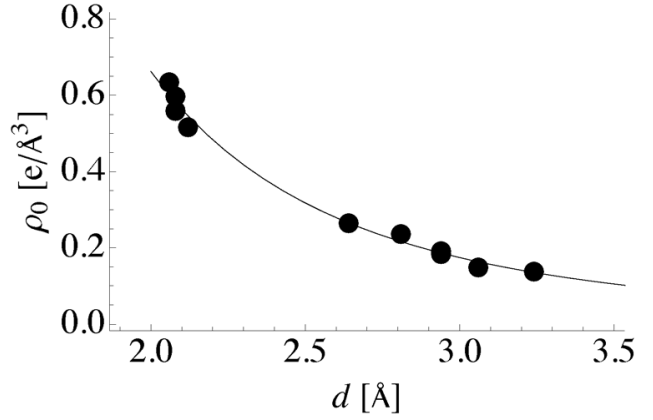

Fig. 11 Charge density at the bond critical point versus internuclear separation. The fit line is given by $\rho_{0}=6.489 d^{-3.293}$

However, though $\rho_{0}$ correlates with internuclear separation, introducing this property into the bond cutting model by defining the total bonding associated with a nuclear site as:

$$
\rho_{\text {tot }}=\sum_{\text {bond CPs }} \rho_{0}
$$

where the sum is taken over all the bond paths terminating at the nuclear site of interest, does not result in a good correlation with vacancy formation energy, Fig. 12 . This failure of $\rho_{0}$ alone to correlate with the energy required to destroy bond paths has been previously observed. ${ }^{44,58}$ To bring the bond cutting model into agreement with the calculated surface vacancy formation energies we can, instead, include bond path directionality as the total directionality:

$$
D=\sum_{\text {bond CPs }} \min \left(\rho_{0} \tan \theta, \rho_{0} \tan \phi\right),
$$

where the total directionality, $D$, is simply a sum of the smaller of the two angles at each bond point terminating at the nuclear site of interest, which offers an aggregate measure of bonding.

Comparing the total directionality of the bond paths terminating at a silver atom in the bulk to one on the clean (111) surface yields a $D_{\text {surface }} / D_{\text {bulk }}$ ratio of $52 \%$. Thus, the ratio of total directionality is a more accurate predictor of differences in vacancy formation energies than the ratio of the number of bond paths alone. In fact, we found that the unrelaxed vacancy formation energy changes linearly with total directionality, Fig. 13.

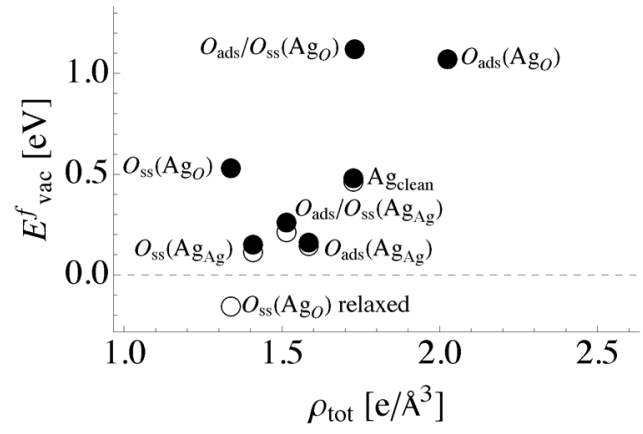

Fig. 12 Total bonding at an atom site defined using the magnitude of the charge density as in eqn (4) versus surface vacancy formation energy in the presence of different oxygen species. The filled (unfilled) circles represent unrelaxed (relaxed) vacancy formation energies. 


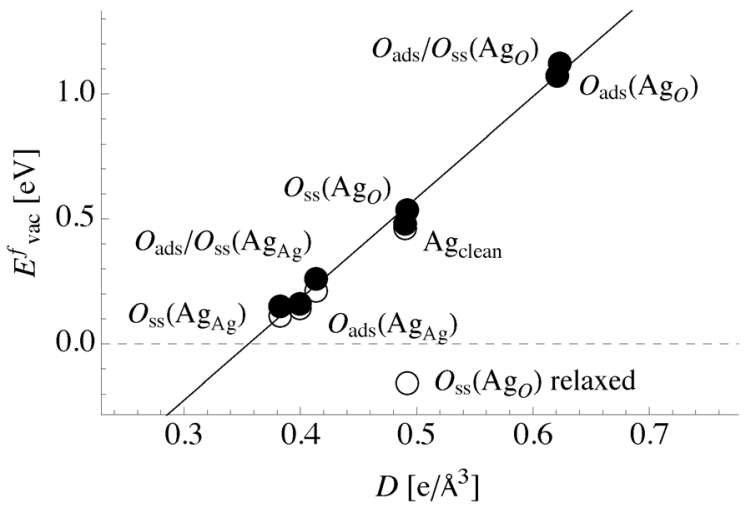

Fig. $13 \mathrm{Ag}(111)$ surface vacancy formation energy in the presence of different oxygen species against the total directionality of the bond paths terminating at the associated surface atom. The filled (unfilled) circles represent unrelaxed (relaxed) vacancy formation energies.

To understand this relationship in more detail, we will now turn to how the bonding in the $\mathrm{Ag}-\mathrm{O}$ system changes in the presence of oxygen.

As we saw in Section 4, when 1/4 ML oxygen adsorbs on the $\mathrm{Ag}(111)$ surface to form $\mathrm{O}_{\mathrm{ads}}$ the bonding topology changes from that found on a clean silver surface. Each $\mathrm{Ag}_{\mathrm{O}}$ gains a directional $\mathrm{Ag}-\mathrm{O}$ bond path at the expense of two less directional $\mathrm{Ag}-\mathrm{Ag}$ surface bond paths. The adsorbed oxygen also perturbs the neighboring bond paths, making the $\mathrm{Ag}_{\mathrm{O}}-\mathrm{Ag}_{\mathrm{O}}$ bond paths more directional than those on a clean $\mathrm{Ag}(111)$ surface and the $\mathrm{Ag}_{\mathrm{Ag}}-\mathrm{Ag}_{\mathrm{O}}$ bond paths less directional. Thus, despite the fact that nine bond paths terminate at the $\mathrm{Ag}_{\mathrm{Ag}}$ atoms and only eight bond paths terminate at the $\mathrm{Ag}_{\mathrm{O}}$ atoms, the total directionality of the former is 0.40 , while $D$ of $\mathrm{Ag}_{\mathrm{O}}$ is 0.62 . When these results are compared to the total directionality of a silver atom on the clean surface, $D=0.45$, we would expect that adsorbed oxygen increases the vacancy formation energy of $\mathrm{Ag}_{\mathrm{O}}$ but decreases that of $\mathrm{Ag}_{\mathrm{Ag}}$, as we saw in Table 1. When ionic relaxations are included, both vacancies relax to the $\mathrm{Ag}_{\mathrm{Ag}}$ vacancy structure to maximize the number of $\mathrm{Ag}-\mathrm{O}$ bond paths. However, because the bonding topology in the relaxed structure is identical to that of the unrelaxed $\mathrm{Ag}_{\mathrm{Ag}}$ vacancy, the change in energy between the unrelaxed and relaxed $\mathrm{Ag}_{\mathrm{Ag}}$ vacancy structures is small.

The fact that introducing subsurface oxygen into the system with $\mathrm{O}_{\text {ads }}$ leads only to a small change in surface vacancy formation energy can also be rationalized in terms of oxygen induced differences in bond path directionality. When both $\mathrm{O}_{\mathrm{ss}}$ and $\mathrm{O}_{\text {ads }}$ are present the $\mathrm{Ag}_{\mathrm{Ag}}$ atoms are again bound to nine atoms and have a total directionality of 0.41. And though the total number of bond paths terminating at the $\mathrm{Ag}_{\mathrm{o}}$ drops from eight to six their total directionality remains at approximately 0.63 because an additional directional $\mathrm{Ag}_{\mathrm{O}}-\mathrm{O}$ bond path is formed at the expense of two less directional $\mathrm{Ag}_{\mathrm{O}}-\mathrm{Ag}_{\mathrm{O}}$ bond paths. These slight increases in directionality are manifested as small increases in the surface vacancy formation energies shown in Table 1.

This trend of directional $\mathrm{Ag}-\mathrm{O}$ bonding increasing the $\mathrm{Ag}_{\mathrm{O}}$ and decreasing the $\mathrm{Ag}_{\mathrm{Ag}}$ surface vacancy formation energy continues when dissolved oxygen is present in the absence of adsorbed oxygen. Like in the previous cases, the $\mathrm{Ag}_{\mathrm{Ag}}$ atoms in this system are bound to the nine nearest neighbor $\mathrm{Ag}$ atoms. However, the total directionality of the bond paths terminating at the $\mathrm{Ag}_{\mathrm{Ag}}$ atoms is only 0.38 because the subsurface oxygen perturbs the $\mathrm{Ag}-\mathrm{Ag}$ bonding more strongly than $\mathrm{O}_{\text {ads }}$, as shown in Section 4. The total directionality of the seven bond paths terminating at each $\mathrm{Ag}_{\mathrm{O}}$ atom is 0.49 . While these total directionalities recover the unrelaxed surface vacancy formation energies shown in Table 1, the effect of ionic relaxations reduces the relaxed $\mathrm{Ag}_{\mathrm{O}}$ vacancy formation energy.

As was shown in Section 4, the $\mathrm{Ag}_{\mathrm{Ag}}$ and $\mathrm{Ag}_{\mathrm{O}}$ vacancies relax to different structures when $\mathrm{O}_{\mathrm{ss}}$ is present without $\mathrm{O}_{\mathrm{ads}}$, where we saw that, while the ionic relaxation associated with the $\mathrm{Ag}_{\mathrm{Ag}}$ vacancy results in no change in bonding and a minor reduction in $E_{\mathrm{vac}}$, relaxation of the $\mathrm{Ag}_{\mathrm{o}}$ vacancy leads to the formation of an additional $\mathrm{Ag}-\mathrm{O}$ bond path, which makes vacancy formation exothermic. Thus, pure subsurface oxygen will induce a restructuring of the $\mathrm{Ag}(111)$ surface wherein vacancies spontaneously form, allowing the subsurface oxygen to become a surface substitutional, which could help explain the increase in surface self-diffusion of silver in an oxygen atmosphere above $700 \mathrm{~K}$, as compared to an oxygen free atmosphere. ${ }^{17-19}$

These trends are summarized graphically in the plot of surface vacancy formation energy versus total directionality in Fig. 13. The dashed horizontal line shows $E_{\mathrm{vac}}=0 \mathrm{eV}$. The filled circles are the values of $E_{\mathrm{vac}}$ without ionic relaxation and the unfilled circles show $E_{\mathrm{vac}}$ with ionic relaxation. The total directionality correlates with the unrelaxed surface vacancy formation energy. When there are no topological changes associated with relaxation $D$ also correlates well with the relaxed surface vacancy formation energy.

\subsection{Chemical trends in surface vacancy formation}

This structure-property relationship between total directionality and surface vacancy formation energy allows us to use simple chemical concepts to predict how the surface vacancy formation energy will change under different atmospheres or with alloying. Such changes could modify the directionality of the surfaceadsorbate bond paths or the surface-surface bond paths.

We would expect, for instance, that the silver surface vacancy formation energy would be decreased further by introducing an element that can form more directional bonds with the silver surface than oxygen, such as sulfur, which adsorbs on the fcc hollow site of the $\mathrm{Ag}(111)$ surface at $1 / 4 \mathrm{ML}$ coverage, ${ }^{85}$ resulting in a reduction in the unrelaxed $E_{\mathrm{vac}}$ of the $\mathrm{Ag}_{\mathrm{Ag}}$ to $0.22 \mathrm{eV}$. As we found in the case of adsorbed oxygen, ionic relaxations play a minor role, reducing $E_{\mathrm{vac}}$ to $0.18 \mathrm{eV}$. This pronounced reduction in the surface vacancy formation energy of silver in the presence of sulfur may help explain the experimentally observed increase in surface self-diffusion seen in this system. ${ }^{86}$

An adsorbate that is more electronegative than oxygen, such as a halogen, can reduce the surface vacancy formation energy below what we found in the presence of oxygen by withdrawing more density from the silver surface bonds. $\mathrm{Cl}$, for instance, 
adsorbs on the fcc hollow site of the Ag(111) surface at 1/4 ML coverage. ${ }^{87,88}$ We found that it reduces $E_{\mathrm{vac}}$ of the $\mathrm{Ag}_{\mathrm{Ag}}$ atoms to $0.20 \mathrm{eV}$, significantly lower than the $0.34 \mathrm{eV}$ found in the presence of $1 / 4 \mathrm{ML}$ adsorbed oxygen. Because chlorine does not form a substitutional species on the $\mathrm{Ag}(111)$ surface $^{87}$ the effect of ionic relaxations are minor, reducing $E_{\mathrm{vac}}$ to $0.16 \mathrm{eV}$.

In contrast to the previous examples, when an electropositive element adsorbs on silver we would expect it to increase the surface vacancy formation energy. Take sodium for example, it will not form directional bonds with the silver surface because its valence density is a consequence of its s-character. Because its electronegativity is less than that of silver's, sodium will donate density to the surface, thereby increasing the directionality of the $\mathrm{Ag}-\mathrm{Ag}$ surface bonds. As expected, when 1/4 ML sodium is adsorbed on the fcc hollow sites of the $\mathrm{Ag}(111)$ surface, we found that the unrelaxed surface vacancy formation increases to $0.59 \mathrm{eV}$ for the $\mathrm{Ag}_{\mathrm{Na}}$ and $0.58 \mathrm{eV}$ for the $\mathrm{Ag}_{\mathrm{Ag}}$ atoms. Note that these effects are not specific to the silver system, as evidenced by the fact that sodium has also been shown to increase the vacancy formation energy on a ruthenium surface. ${ }^{29}$ Because of this fact, we can also consider the effect of alloying.

Take $\mathrm{Cu} / \mathrm{Ag}$ alloys, for example, which are known to have a tendency to segregate. ${ }^{89}$ In the presence of oxygen, copper moves to the $\operatorname{Ag}(111)$ surface due to the fact that copper and oxygen form very directional bonds. ${ }^{90-93}$ This directional $\mathrm{Cu}-\mathrm{O}$ bonding will result in a large $E_{\mathrm{vac}}$ of copper, but will reduce that of any surface silver atoms. We found that when $1 / 4$ of the $\mathrm{Ag}(111)$ surface atoms are substituted with copper, the work required to remove the surface silver atom drops to $0.09 \mathrm{eV}$. This large drop in $E_{\mathrm{vac}}$ is in agreement with the high surface mobility found in $\mathrm{Ag}-\mathrm{Cu}$ particles under air, in which copper is immobile and the surface diffusion of silver is entirely responsible for the formation of sintered necks. ${ }^{94}$

\section{Conclusions}

In summary, we have used DFT calculations to show that dissolved and adsorbed oxygen lower the surface vacancy formation energy of silver. We went on to show that the total directionality of the topological bond paths correlates with these changes in surface vacancy formation energy. We then used this correlation to develop a structure-property relationship to allow us to predict how changing the gas phase or alloying the silver would alter the surface vacancy formation energy. Adsorbed electronegative elements tend to decrease the surface vacancy formation energy by withdrawing density from the silver surface and reducing the directionality of the $\mathrm{Ag}-\mathrm{Ag}$ surface bonds, whereas electropositive adsorbates donate electron density to the silver surface and increase the directionality of $\mathrm{Ag}-\mathrm{Ag}$ surface bonds. These results suggest that, during sintering, surface reactions and other processes that depend critically upon the nature of surface defects selectively alloying or altering the gas phase can have a substantial effect on properties and performance.

\section{Acknowledgements}

We gratefully acknowledge the Australian Research Council and the CINECA award under the ISCRA initiative, for the availability of high performance computing resources and support.

\section{References}

1 M. Doyama and J. S. Koehler, Phys. Rev., 1962, 127, 21-31.

2 A. Zangwill, Physics at Surfaces, Cambridge University Press, New York, 1988.

3 Z. Wang, Y. Li and J. B. Adams, Surf. Sci., 2000, 450, 51-63.

4 J.-M. Wen, J. W. Evans, M. C. Bartelt, J. W. Burnett and P. A. Thiel, Phys. Rev. Lett., 1996, 76, 652-655.

5 A. R. Akbarzadeh, Z. Z. Chen and N. Kioussis, Phys. Rev. B: Condens. Matter Mater. Phys., 2009, 79, 195404.

6 G. Mathieu, P. Gas, A. Combe-Brun and J. Bernardini, Acta Metall. Mater., 1983, 31, 1661-1667.

7 H. E. Collins and P. G. Shewmon, Trans. Metall. Soc. AIME, 1966, 236, 1354-1360.

8 F. Delamre and G. H. Rhead, Surf. Sci., 1971, 28, 267-284.

9 H. Grabke, E. Petersen and S. Srinivasan, Surf. Sci., 1977, 67, 501-516.

10 T. Kunimune, M. Kuramoto, S. Ogawa, M. Nogi and K. Suganuma, IEEE Trans. Compon., Packag., Manuf. Technol., 2013, 3, 363-369.

11 W. Johnson, R. Barrett and W. Nix, Metall. Trans., 1972, 3, 695-698.

12 S. Fujishiro and D. Eylon, Scr. Metall. Mater., 1977, 11, 1011-1016.

13 X. Bao, G. Lehmpfuhl, G. Weinberg, R. Schlogl and G. Ertl, J. Chem. Soc., Faraday Trans., 1992, 88, 865-872.

14 S. R. Seyedmonir, D. E. Strohmayer, G. J. Guskey, G. L. Geoffroy and M. A. Vannice, J. Catal., 1985, 93, 288-302.

15 B. Chalmers, R. King and R. Shuttleworth, Proc. R. Soc. London, Ser. A, 1948, 193, 465-483.

16 A. Moore, Acta Metall. Mater., 1958, 6, 293-304.

17 G. Rhead and H. Mykura, Acta Metall. Mater., 1962, 10, 843-856.

18 G. Rhead, Acta Metall. Mater., 1963, 11, 1035-1042.

19 G. E. Rhead, Acta Metall. Mater., 1965, 13, 223-226.

20 C. Carlisle, T. Fujimoto, W. Sim and D. King, Surf. Sci., 2000, 470, 15-31.

21 J. Schnadt, A. Michaelides, J. Knudsen, R. T. Vang, K. Reuter, E. Lægsgaard, M. Scheffler and F. Besenbacher, Phys. Rev. Lett., 2006, 96, 146101.

22 M. Schmid, A. Reicho, A. Stierle, I. Costina, J. Klikovits, P. Kostelnik, O. Dubay, G. Kresse, J. Gustafson, E. Lundgren, J. N. Andersen, H. Dosch and P. Varga, Phys. Rev. Lett., 2006, 96, 146102.

23 R. Reichelt, S. Gunther, M. Rossler, J. Wintterlin, B. Kubias, B. Jakobi and R. Schlögl, Phys. Chem. Chem. Phys., 2007, 9, 3590-3599.

24 H. Schubert, U. Tegtmeyer, D. Herein, X. Bao, M. Muhler and R. Schlögl, Catal. Lett., 1995, 33, 305-319. 
25 X. Bao, M. Muhler, T. Schedel-Niedrig and R. Schlögl, Phys. Rev. B: Condens. Matter Mater. Phys., 1996, 54, 2249-2262.

26 T. C. R. Rocha, A. Oestereich, D. V. Demidov, M. Havecker, S. Zafeiratos, G. Weinberg, V. I. Bukhtiyarov, A. KnopGericke and R. Schlögl, Phys. Chem. Chem. Phys., 2012, 14, 4554-4564.

27 W.-X. Li, C. Stampfl and M. Scheffler, Phys. Rev. B: Condens. Matter Mater. Phys., 2002, 65, 075407.

28 M. Schmid, G. Leonardelli, M. Sporn, E. Platzgummer, W. Hebenstreit, M. Pinczolits and P. Varga, Phys. Rev. Lett., 1999, 82, 355-358.

29 C. Stampfl and M. Scheffler, Phys. Rev. B: Condens. Matter Mater. Phys., 2002, 65, 155417.

30 W.-X. Li, C. Stampfl and M. Scheffler, Phys. Rev. B: Condens. Matter Mater. Phys., 2003, 68, 165412.

31 W.-X. Li, C. Stampfl and M. Scheffler, Phys. Rev. Lett., 2003, 90, 256102.

32 W.-X. Li, C. Stampfl and M. Scheffler, Phys. Rev. B: Condens. Matter Mater. Phys., 2003, 67, 045408.

33 C. Rehren, X. B. M. Muhler, R. Schlögl and G. Ertl, Z. Phys. Chem., 1991, 174, 11-52.

34 G. I. N. Waterhouse, G. A. Bowmaker and J. B. Metson, Appl. Catal., A, 2004, 265, 85-101.

35 G. I. Waterhouse, G. A. Bowmaker and J. B. Metson, Appl. Surf. Sci., 2003, 214, 36-51.

36 X. Bao, M. Muhler, B. Pettinger, R. Schlögl and G. Ertl, Catal. Lett., 1993, 22, 215-225.

37 G. J. Millar, M. B. Nelson and P. J. R. Uwins, J. Catal., 1997, 169, 143-156.

38 P. Hohenberg and W. Kohn, Phys. Rev., 1964, 136, B864-B871.

39 R. F. W. Bader, Atoms in Molecules. A Quantum Theory, Clarendon Press, Oxford, 1990.

40 The Quantum Theory of Atoms in Molecules: From Solid State to DNA and Drug Design, ed. C. F. Matta and R. J. Boyd, Wiley-VCH, 2007.

41 A. Martn Pendás, A. Costales and V. Luaña, Phys. Rev. B: Condens. Matter Mater. Phys., 1997, 55, 4275-4284.

42 P. F. Zou and R. F. W. Bader, Acta Crystallogr., Sect. A: Found. Crystallogr., 1994, 50, 714-725.

43 M. E. Eberhart, D. P. Clougherty and J. M. MacLaren, J. Am. Chem. Soc., 1993, 115, 5762-5767.

44 T. E. Jones, M. E. Eberhart, S. Imlay, C. Mackey and G. B. Olson, Phys. Rev. Lett., 2012, 109, 125506.

45 Morse Theory, ed. J. Milnor, Princeton University Press, 1963.

46 T. E. Jones and M. E. Eberhart, J. Chem. Phys., 2009, 130, 204108.

47 T. E. Jones and M. E. Eberhart, Acta Crystallogr., Sect. A: Found. Crystallogr., 2009, 65, 141-144.

48 P. Coppens, X-Ray Charge Densities and Chemical Bonding, Oxford University Press, Cambridge, England, 1997.

49 T. S. Koritsanszky and P. Coppens, Chem. Rev., 2001, 101, 1583-1628.

50 B. B. Iversen, F. K. Larsen, M. Souhassou and M. Takata, Acta Crystallogr., Sect. B: Struct. Sci., 1995, 51, 580-591.

51 T. A. Keith, R. F. W. Bader and Y. Aray, Int. J. Quantum Chem., 1996, 57, 183-198.
52 R. F. W. Bader, J. Phys. Chem. A, 1998, 102, 7314-7323.

53 R. F. W. Bader and D.-C. Fang, J. Chem. Theory Comput., 2005, 1, 403-414.

54 G. R. Runtz, R. F. W. Bader and R. R. Messer, Can. J. Chem., 1977, 55, 3040-3045.

55 K. Collard and G. G. Hall, Int. J. Quantum Chem., 1977, 12, 623-637.

56 N. Castillo, C. F. Matta and R. J. Boyd, Chem. Phys. Lett., 2005, 409, 265-269.

57 M. E. Eberhart, Philos. Mag. A, 1996, 73, 47-60.

58 N. Kioussis, M. Herbranson, E. Collins and M. E. Eberhart, Phys. Rev. Lett., 2002, 88, 125501.

59 M. Eberhart, Acta Mater., 1996, 44, 2495-2504.

60 X. F. Wang, T. E. Jones, W. Li and Y. C. Zhou, Phys. Rev. B: Condens. Matter Mater. Phys., 2012, 85, 134108.

61 M. E. Eberhart and T. E. Jones, Phys. Rev. B: Condens. Matter Mater. Phys., 2012, 86, 134106.

62 T. Poston and I. Stewart, Catastrophe Theory and its Applications, Dover, New York, 1981.

63 R. F. W. Bader, T. T. Nguyen-Dang and Y. Tal, J. Chem. Phys., 1979, 70, 4316-4329.

64 R. F. W. Bader, T. T. Nguyen-Dang and Y. Tal, Rep. Prog. Phys., 1981, 44, 893.

65 T. E. Jones, M. E. Eberhart and D. P. Clougherty, Phys. Rev. Lett., 2010, 105, 265702.

66 P. Ayers and S. Jenkins, J. Chem. Phys., 2009, 130, 154104.

67 A. Guevara-García, E. Echegaray, A. Toro-Labbe, S. Jenkins, S. Kirk and P. W. Ayers, J. Chem. Phys., 2011, 134, 234106.

68 P. Giannozzi, S. Baroni, N. Bonini, M. Calandra, R. Car, C. Cavazzoni, D. Ceresoli, G. L. Chiarotti, M. Cococcioni, I. Dabo, A. Dal Corso, S. de Gironcoli, S. Fabris, G. Fratesi, R. Gebauer, U. Gerstmann, C. Gougoussis, A. Kokalj, M. Lazzeri, L. Martin-Samos, N. Marzari, F. Mauri, R. Mazzarello, S. Paolini, A. Pasquarello, L. Paulatto, C. Sbraccia, S. Scandolo, G. Sclauzero, A. P. Seitsonen, A. Smogunov, P. Umari and R. M. Wentzcovitch, J. Phys.: Condens. Matter, 2009, 21, 395502.

69 J. P. Perdew, K. Burke and M. Ernzerhof, Phys. Rev. Lett., 1996, 77, 3865-3868.

70 H. J. Monkhorst and J. D. Pack, Phys. Rev. B: Condens. Matter Mater. Phys., 1976, 13, 5188-5192.

71 N. Marzari, D. Vanderbilt, A. De Vita and M. C. Payne, Phys. Rev. Lett., 1999, 82, 3296-3299.

72 TECD, 2004, http://inside.mines.edu/meberhar/MTG.

73 P. Villars and L. D. Calvert, Pearson's Handbook of Crystallographic Data for Intermetallic Phases, American Society for Metals, Metals Park, OH, 1985, vol. 3.

74 T. Hoshino, T. Mizuno, M. Asato and H. Fukushima, Mater. Trans., 2001, 42, 2206-2215.

75 J.-P. Crocombette, H. de Monestrol and F. Willaime, Phys. Rev. B: Condens. Matter Mater. Phys., 2002, 66, 024114.

76 J. McGervey and W. Triftshauser, Phys. Lett. A, 1973, 44, 53-54.

77 W. Triftshauser and J. McGervey, Appl. Phys., 1975, 6, 177-180.

78 M. Doyama and J. S. Koehler, Phys. Rev., 1960, 119, 939. 
79 R. O. Simmons and R. W. Balluffi, Phys. Rev., 1960, 119, 600-605. 80 O. Knop, R. J. Boyd and S. C. Choi, J. Am. Chem. Soc., 1988, 110, 7299-7301.

81 I. Alkorta, I. Rozas and J. Elguero, Struct. Chem., 1998, 9, 243-247. 82 G. V. Gibbs, F. C. Hill, M. B. Boisen and R. T. Downs, Phys. Chem. Miner., 1998, 25, 585-590.

83 N. Castillo, K. N. Robertson, S. C. Choi, R. J. Boyd and O. Knop, J. Comput. Chem., 2008, 29, 367-379.

84 G. Gibbs, N. Ross, D. Cox, K. Rosso, B. Iversen and M. Spackman, Phys. Chem. Miner., 2014, 41, 17-25.

85 L. A. Soria, G. Zampieri and M. L. Martiarena, J. Phys. Chem. C, 2011, 115, 9587-9592.

86 F. Delamre and G. H. Rhead, Surf. Sci., 1967, 7, 175-178.

87 N. H. de Leeuw, C. J. Nelson, C. R. A. Catlow, P. Sautet and W. Dong, Phys. Rev. B: Condens. Matter Mater. Phys., 2004, 69, 045419.
88 P. Gava, A. Kokalj, S. de Gironcoli and S. Baroni, Phys. Rev. B: Condens. Matter Mater. Phys., 2008, 78, 165419.

89 K. Terakura, T. Oguchi, T. Mohri and K. Watanabe, Phys. Rev. B: Condens. Matter Mater. Phys., 1987, 35, 2169-2173.

90 S. Piccinin, S. Zafeiratos, C. Stampfl, T. W. Hansen, M. Hävecker, D. Teschner, V. I. Bukhtiyarov, F. Girgsdies, A. Knop-Gericke, R. Schlögl and M. Scheffler, Phys. Rev. Lett., 2010, 104, 035503.

91 S. Piccinin, C. Stampfl and M. Scheffler, Phys. Rev. B: Condens. Matter Mater. Phys., 2008, 77, 075426.

92 S. Piccinin, C. Stampfl and M. Scheffler, Surf. Sci., 2009, 603, 1467-1475.

93 A. Soon, M. Todorova, B. Delley and C. Stampfl, Phys. Rev. B: Condens. Matter Mater. Phys., 2006, 73, 165424.

94 S. J. Kim, E. A. Stach and C. A. Handwerker, Appl. Phys. Lett., 2010, 96, 144101. 